\title{
Dissertation Abstract
}

\section{Exploring Manhood, Masculinities and the Roles of Men Regarding Pregnancy and Childbirth in a Humanitarianized War Zone of Eastern Democratic Republic of Congo}

\section{Author: Felicien Maisha, University of Florida, Department of Anthropology}

This study aims to understand men and masculinities in the eastern Democratic Republic of Congo where violence, armed conflicts, and the inability of the state to meet the basic needs of its population have justified the presence of heavy humanitarian aid interventions and probably shaped men's behaviors.

Through this study, I seek to place men first in their local socio-cultural context in order to analyze their behavior and the roles men are called to play within their community. I put my particular attention on the global health agenda and guidelines interrogating how they materialize at the local level, taking the example of the push to increase socalled men's involvement in prenatal care service. The following questions helped me to explore issues regarding masculinities in Goma and Kanyarutshinya. Who do we call a man? How does one become or un-become a man in the context of Goma and Kanyarutshinya, two specific locations where I conducted my research. Using ethnographic participant observation, I also collected my data using in-depth interviews, key informant interviews, focus group discussion, life histories, and archival data.

My analysis of the data collected has shown that war and armed conflict have deteriorated the status of men in the region and consequently, they felt deprived of their masculinity. Men living in a rural setting were attached to the local traditional values defining masculinity and these motivated their behaviors. In urban areas, on the contrary, men were more exposed to intercultural practices and had easy access to media and modern communication channels and were less concerned with local values of masculinities.

Everywhere, the precariousness of masculinity was observed; men, despite their efforts to avoid losing their masculinity used the so-called well-known concept of 'debrouillez-vous', failed despite everything.

Finally, I found that the call for 'men's involvement' regarding pregnancy and childbirth in Goma and Kanyarutshinya using the international guidelines was almost irrelevant because men were already involved using the local standards. However, the biomedical prenatal care for men in Goma called CPN Papa failed to meet men's expectations and rejected them, thereby undermining the program's goals.

This dissertation abstract was submitted to the Graduate School of the University of Florida in Fall, 2020.

Maisha, Felicien (2021) Exploring Manhood, Masculinities and the Roles of Men Regarding Pregnancy and Childbirth in a Humanitarianized War Zone of Eastern Democratic Republic of Congo. [Doctoral Dissertation, University of Florida], New Florida Journal of Anthropology, 1(2), 12 DOI 10.32473/nfja.v1i2.127086 